\title{
Cyclin-dependent Kinase 8/19 Inhibitor BCD 115
}

National Cancer Institute

\section{Source}

National Cancer Institute. Cyclin-dependent Kinase 8/19 Inhibitor BCD 115. NCI

Thesaurus. Code C148166.

An orally bioavailable inhibitor of cyclin dependent kinases 8 and 19 (CDK8/19), with potential antineoplastic and chemoprotective activities. Upon oral administration, CDK8/19 inhibitor BCD 115 binds to and inhibits the activity of CDK8/19, which prevents activation of CDK8/19-mediated oncogenic signaling pathways, blocks selective transcription of certain tumor promoting genes, and inhibits proliferation of CDK8/19overexpressing tumor cells. CDKs are serine/threonine kinases involved in the regulation of the cell cycle and may be overexpressed in certain cancer cell types. CDK8 plays a key role in transcription regulation and is an important oncogenic driver in a variety of cancer cell types. 